\title{
ELEMENTOS PARA UN PLAN DE EDUCACIÓN LITERARIA
}

\author{
LUIS GaLVÁN \\ Universidad de Navarra
}

La educación literaria en el sistema escolar necesita un plan continuo, progresivo y bien estructurado. La planificación suele quedar descuidada en los trabajos sobre enseñanza de la literatura, que abordan preferentemente los extremos del proceso: los principios y objetivos, y la práctica en el aula. En estas áreas hay acuerdo: la literatura es un componente fundamental de la educación porque facilita el dominio del lenguaje, da a conocer formas de vida y proyectos imaginativos variados y enriquecedores, sitúa en las tradiciones culturales hispánica y occidental, etc.; el alumno ha de convertirse en un lector sensible e interesado; este proceso tendrá lugar mediante la lectura de textos adecuados y significativos, y también mediante la composición de textos propios ${ }^{1}$. Ahora bien, ¿cómo se llegará, por la suma de lecturas y composiciones, a la cultura y sensibilidad que se consideran esenciales? Esto exige desarrollos más amplios y precisos, que son todavía una tarea pendiente ${ }^{2}$.

En tales circunstancias, pueden resultar orientadores los planes impulsados e inspirados por Northrop Frye desde hace décadas en los Estados

\footnotetext{
${ }^{1}$ Ver, por ejemplo, Lázaro 1973; las opiniones recogidas en Lázaro 1974; Coseriu 13-15 y 31-32; Garrido 1994: 15-27; Mendoza; Reyzábal; el capítulo de Ángel García Galiano en Garrido 2000: 317-47. En los congresos sobre didáctica de la literatura suele mostrarse, sobre todo, el interés de ciertos textos y ciertas técnicas en el aula (ver, por ejemplo, Galán, Gúgel, Sainz de Vicuña y Suárez; Orive; Noya y Posada).

2 «Un currículo no debe establecerse de forma puntual para un curso o ciclo, sino de forma coordinada para, por ejemplo, todo lo que es la enseñanza obligatoria. Esto supone tener una visión unitaria de la Enseñanza de la Literatura desde el parvulario hasta la Educación Secundaria, y coordinar igualmente la formación del profesorado de estos distintos niveles» (García Rivera 102). La propia García Rivera $(73,80-81,117,262)$ da algunos principios generales para semejante programación, pero sus propuestas más concretas solo abarcan un curso o un ciclo. También Colomer (1996: 138) llama la atención hacia la dificultad de establecer tal planificación y la escasez de renovación didáctica en ese campo.
}

Rlit, LXVI, 132 (2004), 537-554 
Unidos de América y en Canadá. Han visto la luz muchas publicaciones dirigidas a alumnos y profesores desde la educación infantil hasta la universitaria, y se han fundado centros para la investigación y formación en este campo. El fundamento teórico de todo este trabajo permite fácilmente transferirlo, con los cambios necesarios, a otras tradiciones lingüísticas. Por eso, en las páginas que siguen presento una síntesis de las ideas fundamentales y de los planes desarrollados, con algunas propuestas para la adaptación a la literatura española ${ }^{3}$.

\section{LA VISIÓN GLOBAL DE LA LITERATURA Y SU FUNCIÓN EN LA ENSEÑANZA}

Un plan de educación literaria que aspire a una validez general necesita fundarse en una visión de la literatura lo más amplia posible. Los métodos son muchos y cada uno privilegia determinados textos y enfoques; pero todos forman una sola disciplina, que se puede llamar «Ciencia de la Literatura» ${ }^{4}$. La unidad de esta disciplina reposa sobre la unidad de la literatura. Esta última no puede concebirse de manera preceptiva, pues aparecerían ipso facto irregularidades y márgenes que destruirían la unidad; tampoco basta con la mera acumulación de todas las obras, como no basta la acumulación de líneas, formas y volúmenes para constituir la geometría. La unidad proviene de unos principios informadores del arte verbal, que se manifiestan en cada una de las obras. Esos mismos principios son los conceptos fundamentales de la disciplina, y por tanto los que permiten articular su enseñanza.

Frye considera que existen dos principios formales de la literatura. El primero es la metáfora, la identificación verbal entre dos seres. El segundo es la fábula, el discurrir de la acción de un personaje. La metáfora y en general los fenómenos de asociación dan lugar a la imaginería literaria, que se organiza en dos esquemas principales, el cíclico y el dialéctico. Son cíclicas las imágenes que se distribuyen a lo largo de un proceso de naci-

\footnotetext{
${ }^{3}$ Para las ideas de Northrop Frye sobre la literatura, utilizo Frye 1957, 1963, 1976 y 1990; sus escritos sobre educación están recopilados en Frye 2000; para los informes y planes de enseñanza que cuentan con su participación o que se elaboran de acuerdo con sus ideas, utilizo "An Articulated English Program»; Frye 1962; la serie Literature: Uses of the Imagination, editada bajo la supervisión de Frye; la antología The Practical Imagination, editada por Frye, Baker y Perkins; Sloan (agradezco a Megan Mercedes Echevarría, de University of Rhode Island, su imprescindible ayuda en relación con Literature: Uses of the Imagination). En el texto del artículo no precisaré las referencias a aspectos conjuntos de dichos libros y planes, sino sólo las pertinentes para citas o paráfrasis y para las diversas posturas en torno a un asunto.

${ }^{4}$ Frye, dentro de la tradición anglosajona, emplea el término «Criticism», pero deja claro que lo concibe como una ciencia (Frye 1957: 4-8 y 15-20; Frye 1963: 7-8), aunque no privada de cierto componente artístico.
} 
miento, maduración, vejez, y muerte que prepara un renacimiento, como el curso solar del día y del año, o las generaciones naturales. Son dialécticas las que se reparten en dos polos opuestos, que Frye llama «apocalíptico» o divino y «demoníaco»; esos dos polos tienen su analogía en forma terrenal, que son el mundo de la «inocencia» — con reyes justos, padres buenos, amigos fieles, animales domésticos, etc. - y el de la «experiencia» - con tiranos, madrastras, traidores, fieras y demás-. Cada una de estas unidades es un arquetipo. En cuanto a la fábula, aparece en cuatro formas básicas: la comedia es un movimiento ascendente, del descontento a la satisfacción (de lo demoníaco a lo apocalíptico, o de la experiencia a la inocencia); la tragedia, el descendente; el romance, un movimiento que discurre siempre en un nivel elevado; y la ironía o sátira, el movimiento que empieza, discurre y termina en el nivel inferior, con limitaciones y sufrimiento continuos.

De acuerdo con Frye, esas formas principales de la literatura se manifiestan con especial claridad en los mitos y los cuentos fantásticos. A lo largo de la historia aparece una exigencia de realismo, es decir, de adaptación a lo que se consideran elementos y motivaciones plausibles en el mundo conocido por todos, y la literatura responde a esa exigencia mediante el «desplazamiento». Los arquetipos y las fábulas son esencialmente los mismos, pero al desplazarse se manifiestan en formas más cercanas a los hechos y las convicciones usuales. Si en el mito un personaje se metamorfosea, en la épica y la novela simplemente se asocia o se compara con animales o fenómenos naturales; si en el mito muere y resucita, en formas desplazadas finge morir, o sufre un enajenamiento o una enfermedad transitorios, etc. Otra consecuencia del desplazamiento es que las fábulas no se mantienen puras; puede haber, por ejemplo, comedias más bien irónicas y más bien románticas.

La obra literaria se experimenta de dos maneras. Frye las compara con las experiencias corrientes de la música y de la pintura. En primer lugar, uno va leyendo o escuchando de forma sucesiva: sigue la secuencia verbal desde el principio hasta el fin. Cuando se alcanza este punto, se ven todos los elementos en simultaneidad, cada uno en el lugar que le corresponde. Frye llama «fábula» al primer aspecto y «tema» o «sentido» al segundo. Una experiencia completa de la obra no puede prescindir de ninguno.

Estas ideas dan forma al plan de educación literaria. Se trata de desplegar toda la literatura desde tales principios, de acuerdo con su orden interno y con la capacidad de atención, la memoria y el sentido crítico de los alumnos. La enseñanza continua y sistemática hará posible que se adquieran inductivamente las nociones de metáfora, fábula, simbolismo cíclico y dialéctico, etc., y que se posean como hábitos o destrezas. No se trata de enseñar directamente esos conceptos; sólo en etapas superiores, cuando sea oportuno, se abordarán de forma consciente y reflexiva. 
El objetivo es formar lectores con interés y capacidad crítica. Al final de la educación literaria escolar, los alumnos deben estar preparados para leer bien cualquier obra. No se trata de que necesariamente lean las obras mejores y fundamentales en los años escolares. Basta con fortalecer su imaginación y sensibilidad, y es de esperar que lleguen a tales obras en algún momento de su vida, de acuerdo con las circunstancias personales de cultivo y madurez. La capacidad lectora los hace, además, aptos para participar creativa y responsablemente en las demás áreas de la vida, porque les da un dominio más perfecto del lenguaje y las convenciones de la comunicación, y los familiariza con los proyectos imaginativos desplegados en las obras literarias, que forman una visión cívica y social. También en este aspecto se pueden asumir los planes desarrollados en torno a Frye, pues se destinan de forma general a una sociedad moderna, plural y democrática; no se ciñen a situaciones de partida y a objetivos específicos de la Norteamérica del siglo XX, ni tratan de imponer la completa conformidad con el entorno sociopolítico. Por su misma validez general, no resultan inéditas todas las ideas: algunos elementos de estos planes coinciden con propuestas aparecidas en España en las últimas décadas, como se irá señalando a lo largo de los párrafos siguientes.

\section{PRIMERA ETAPA: HASTA LOS OCHO AÑOS}

La educación literaria puede comenzar tan pronto como el niño empieza a usar el lenguaje, y precisamente tal cual lo hace, de una forma espontánea y lúdica. Escuchar cuentos y poesías y dejarse encantar por el relato o el sonido es la experiencia literaria primordial; se da en el entorno familiar y debe prolongarse en la escuela ${ }^{5}$. Esta aportará continuidad y orden, con el objetivo de construir la base de una educación más detenida y precisa en las etapas siguientes ${ }^{6}$.

\footnotetext{
${ }^{5}$ Como escribe Rafael Lapesa, «es preciso que desde la escuela misma se eduque la sensibilidad literaria con lecturas y recitaciones, sin más comentarios que los imprescindibles para que los niños entiendan el sentido inmediato de las obras y puedan ser ganados, ya por la impresión de su belleza, ya por el interés de la acción narrada o puesta en escena» (en Lázaro 1974: 93-94).

${ }^{6}$ Eugenio de Bustos, ante una pregunta por los objetivos del profesor de Literatura en las enseñanzas media y universitaria, señala que la Literatura debe estar presente en la enseñanza primaria «porque [...] es disparatado plantear ningún tipo de objetivo para un determinado nivel si no se cuenta con el punto de partida, y éste es -o debiera ser- el objetivo logrado en el nivel anterior» (en Lázaro 1974: 71). Por tanto, son incompletos los planes que sugieren lecturas apropiadas para las capacidades lingüísticas y los intereses propios de cada edad, pero pierden de vista la necesidad de poner, junto a la afición, una base de conocimientos para la etapa siguiente (como sucede, por ejemplo, en Esquer 69-71; Castro 175-79, 686-89).
} 
En primer lugar ha de ponerse de relieve el valor del sonido. Según Frye (2000: 238-39), el alumno podrá sentir que la poesía es movimiento y sonido; que existe con independencia de las palabras que se hallan en un libro; bien puede percibir la diferencia entre determinados ritmos y versos sin necesidad de conocer sus nombres técnicos. La educación literaria en los primeros años consistirá principalmente en juegos con los sonidos: las onomatopeyas y las formaciones expresivas; la disposición en patrones reconocibles de ritmo y rima; los juegos de palabras, que llaman la atención hacia problemas del sentido; las enumeraciones y catálogos, con su poder evocador. Todos estos recursos abundan en las canciones y poesías infantiles, en la lírica de tipo popular, y en las obras de poetas cultos que se inspiran en esas tradiciones?

Progresivamente se puede emprender la tarea de entrenar el oído de los niños con ritmos característicos de la tradición literaria: primero los populares, como los versos hexasílabos, octosílabos, y combinaciones de arte menor como la seguidilla; más adelante, formas más cultas y sutiles como los endecasílabos y los alejandrinos.

Las adivinanzas forman una categoría propia. Familiarizan a los niños con la identificación, la analogía, la asociación. Describen una cosa no en los términos propios, sino en términos de otra cosa, o de las impresiones y sensaciones que despierta; o bien descubre posibilidades inéditas en el uso normal del significante. Es evidente la relación de estos fenómenos con elementos nucleares de la literatura, como la metáfora y la desautomatización del lenguaje. Si se prolonga y cultiva el interés y la diversión que hallan los niños en las adivinanzas, podrán resultarles naturales las metáforas y símbolos que encuentren más adelante en obras difíciles.

La actividad principal, evidentemente, es la recitación por el profesor. Los niños pronto quieren sumarse, coreando la respuesta de la adivinanza o la palabra que contiene la rima. El movimiento acompasado con la recitación facilita que se perciba el ritmo. Después, hay que favorecer que los niños se manifiesten con los mismos recursos que van percibiendo: aliteraciones, onomatopeyas y juegos de palabras; imágenes y asociaciones. Más adelante se tratará de que compongan sus propias adivinanzas, enumeraciones rítmicas, catálogos y rimas, sea en trabajo individual, sea en equipos o con tormenta de ideas ${ }^{8}$.

Los cuentos populares y de hadas proporcionan la introducción a la narrativa. Se trata de acostumbrar a los niños a seguir con atención los

\footnotetext{
${ }^{7}$ Moreno Báez destaca el valor educativo de la poesía popular de los siglos XV y XVI y de los romances, y de sus imitadores cultos desde el Siglo de Oro hasta el XX (en Lázaro 1974: 106); Pelegrín (1987) analiza el ritmo, las estructuras binarias y las acumulaciones en la poesía de tipo popular escrita por Juan Ramón Jiménez, Federico García Lorca, Rafael Alberti y Nicolás Guillén.

${ }^{8}$ Ver también técnicas y modelos en Moreno; Muñoz.
} 
relatos completos, primero narrados por el profesor y después, según vayan siendo capaces, leídos por ellos mismos. El contenido puede ser variado, desde la pura fantasía hasta aspectos llamativos del mundo que rodea a los niños: todo lo que pueda atraer su interés por lo nuevo. Mitos, leyendas y relatos bíblicos pueden tener un papel importante en los primeros contactos con la Literatura; pero una ocupación más intensa con ellos se reserva para la segunda etapa ${ }^{9}$.

Durante la iniciación a la Literatura, lo importante es recrearse en la poesía o el relato tal como son. No hay lugar para los comentarios sobre los textos, ni expuestos por el profesor ni solicitados a los alumnos; en todo caso, se podría invitar a los niños a formular preguntas, pero sin imponer ni exigir respuestas. Proponer interpretaciones puede ser el comienzo del fin de la Literatura: sugiere que la poesía y la ficción significan alguna otra cosa, y que esta se expone más clara y naturalmente en otro lenguaje.

\section{SEGUNDA ETAPA: HASTA LOS DOCE AÑOS}

En la segunda etapa el alumno empieza a tomar conciencia de las formas y temas que vertebran la literatura. El procedimiento debe ser inductivo: la lectura y el trabajo detenido sobre los textos, con la dirección del profesor. Como los mitos, las leyendas nacionales y la Biblia son los principales repertorios de motivos para la cultura occidental, constituyen un material de trabajo imprescindible en esta etapa.

El objetivo es que se alcance familiaridad con elementos literarios convencionales. Para el aspecto narrativo de los textos, lo principal son los tipos de fábula: comedia, romance, tragedia e ironía. Frye considera que debe prestarse atención preferente a la comedia y el romance porque son los que despiertan una simpatía más inmediata en el lector poco forma$\mathrm{do}^{10}$, y porque la tragedia y la ironía se presentan muchas veces como parodia de aquellos dos. También se examinarán los tipos de personajes asociados a cada fábula, teniendo en cuenta su poder de acción y sus funciones; y las localizaciones y ambientes. Con esto se manifestará otro conjunto de convenciones, la imaginería cíclica y dialéctica.

\footnotetext{
${ }^{9}$ Campbell, McDonald, Parsons, Sparks y Theall (30-31) consideran muy valioso que el niño esté familiarizado, desde los primeros años, con mitos, leyendas y la Biblia, además de canciones infantiles y cuentos de hadas; en cambio, «An Articulated English Program» (13) menciona solo leyendas y cuentos en la primera etapa, y reserva los mitos y la Biblia para la segunda. Frye subraya varias veces $(2000: 135,202-03,437,443)$ la importancia de los mitos y la Biblia en la enseñanza elemental de la Literatura, sin señalar un lugar preciso.

${ }^{10}$ Sloan (75-82) muestra que las fábulas irónicas y trágicas tienen un papel secundario, aunque no irrelevante, en los relatos infantiles.
} 
Las lecturas pueden dividirse en dos grupos. En primer lugar están los relatos de mitos clásicos, de la Biblia y de la historia y leyenda nacional; en el caso de la literatura española quizá conviene incluir en la última categoría algunos personajes propiamente literarios que se han convertido en leyenda o mito y se han cultivado continuamente, como los pícaros, Don Quijote y Don Juan Tenorio. Está claro que no se puede abordar por el momento la lectura de las obras originales completas, la Odisea, la Biblia, el Cantar de mio Cid o el Quijote. En esta etapa son necesarias antologías y versiones adaptadas ${ }^{11}$. El segundo grupo de lecturas consiste en obras infantiles y juveniles que respondan a la diversidad de capacidades lectoras y de intereses de los alumnos. Es necesario que la variedad no sea meramente temática, sino también formal, y este segundo aspecto debe constituir el foco de atención ${ }^{12}$.

El trabajo sobre lo leído se orientará hacia las estructuras y convenciones. Lo primero es el análisis del texto; han de guiarlo preguntas como: ¿es fantástico o realista?; ¿termina bien o mal?; ¿por qué se desencadena la historia?; ¿hay algún acontecimiento clave para el desenlace?; ¿quién es el personaje principal?; ¿es simpático o antipático?; ¿qué poderes tiene?; ¿y los demás personajes?; ¿dónde y cuando sucede la historia?; ¿qué sensaciones y expectativas aporta la localización? El objetivo es una percepción abstracta de la fábula y la imaginería. Las técnicas pueden variar; quizá no convenga plantear las cuestiones directamente en espera de una respuesta, sino desencadenar reacciones imaginativas en los alumnos. El profesor que cuenta o lee en voz alta puede detenerse en un punto clave y preguntarles qué esperan que suceda a continuación; o proponerles algún cambio en la localización o el elenco de personajes y ver cómo reaccionan, etc.

Después, el profesor invitará a sugerir semejanzas con otros relatos. Hay

${ }^{11}$ Uno de los primeros volúmenes escolares inspirados por Frye fue un manual de mitología (Macpherson); originariamente se dedicó a alumnos de catorce a quince años, con éxito, pero también se comprobó que daba buenos resultados en cursos más tempranos (ver Frye 2000: 193, 632). No es un diccionario ni un repertorio, sino un conjunto de relatos con conexión temática y con interés argumental, escritos de forma atractiva, además de informativa. En España, son ejemplares algunas obras del primer tercio del siglo Xx: Ángel Cruz Rueda recibió el Premio Nacional de Literatura de 1929 por Las gestas heroicas castellanas contadas a los niños, versiones de las historias del rey godo don Rodrigo, Bernardo del Carpio, Fernán González, los Siete Infantes de Lara y el Cid; Alejandro Casona recibió el mismo premio en 1932 por Flor de leyendas, con los relatos de Nala y Damayanti, Lohengrin, Héctor y Aquiles, los Nibelungos, Roldán, el destierro del Cid, Guillermo Tell, y otros. Bravo-Villasante (212-16) recoge y comenta una extensa lista de adaptaciones escritas en el siglo XX.

${ }^{12}$ Frye (2000: 230-31) advierte que muchas lecturas no representan más que un tipo de fábula y una misma serie de convenciones desde el punto de vista formal, por más que se varíen los contenidos. Por eso, para orientar el trabajo con literatura infantil son de interés tanto un repertorio amplio y detallado (por ejemplo, González) como los estudios analíticos (Benito, Montes, Pérez y Remacha; López Tamés; Colomer 1999). 
que tener en cuenta y valorar toda la experiencia verbal del alumno, sin limitarse a un campo estrictamente literario. Las semejanzas pueden ser de distintos mitos entre sí, como el de Ulises y el de Eneas; de mitos con leyendas y con historias bíblicas; de estos con relatos literarios, infantiles o no; de todo ese corpus con cuentos populares, hechos históricos o de actualidad, películas, series televisivas, anuncios comerciales, etc. ${ }^{13}$ Esta actividad descubre la difusión de las estructuras míticas y por tanto sugiere su importancia en la configuración de la imaginación personal, social y cultural. A continuación, una mirada más atenta al pormenor revela las diferencias entre los relatos con semejanzas estructurales; esto sirve de introducción al rigor y al detalle en el análisis, da algunas claves de sentido, y proporciona un concepto fundamental de la literatura, el de desplazamiento de los patrones míticos hacia lo aceptable, lo verosímil, lo contemporáneo, etc.

Este último análisis se puede llevar a la práctica de la escritura, con la tarea de hacer versiones desplazadas de relatos o descripciones. Se situará un mito o un cuento de hadas en un entorno contemporáneo; o se modificará el curso de los acontecimientos, pasando de una fábula cómica a una trágica ${ }^{14}$. El alumno se familiariza así con los problemas de composición, de organización del conjunto, de orden de los elementos, que son fundamentales para comunicarse con claridad; y con las convenciones de verosimilitud acerca de los motivos de los personajes y el encadenamiento de los sucesos, que pueden hacer más rigurosos y convincentes tanto sus relatos como sus argumentaciones.

Todo el proceso favorecerá naturalmente una cierta memorización de los mitos, las historias bíblicas y las leyendas. Es más fácil para los alumnos recordar una materia cuya estructura entienden y dominan hasta el punto de manipularla en versiones, y cuya importancia perciben porque han descubierto que está presente de muchas formas en el mundo que les rodea. $\mathrm{Y}$ tal posesión en la memoria no es desdeñable, porque los hace dueños de la clave para las muchas alusiones a lo mítico, legendario y bíblico que se encuentran en toda la literatura y el arte occidentales.

${ }^{13}$ Frye (2000: 451-52) propone que este trabajo se dirija desde la obra literaria al universo verbal contemporáneo; Lázaro (1973: 24-27) sugiere el sentido inverso, al menos ocasionalmente. Se trata, claro está, de relacionar la literatura con otros fenómenos más cercanos a la experiencia corriente, no de sustituir aquélla con éstos (contra lo cual previene García Galiano en Garrido 2000: 338).

${ }^{14}$ Sloan (168-77) presenta varias técnicas y ejemplos. Ver también Rodari (54-89), que propone modificaciones de cuentos tradicionales, y trabajos con las funciones descritas por Propp. 


\section{TERCERA ETAPA: HASTA LOS DIECISÉIS AÑOS}

En la tercera etapa empieza la lectura continua de obras literarias, se abordan aspectos más complejos de la simbolización y las técnicas narrativas, y se estimula y se orienta el sentido crítico.

La lectura de poesía, para favorecer la conexión con la etapa anterior, ha de comenzar por textos que posean fuerza de sonido y ritmo y una imaginería rica en metáforas, comparaciones y asociaciones. La selección ha de abarcar textos del pasado y del presente. Los clásicos latinos - bucólicas de Virgilio, odas y epodos de Horacio- han de tener un puesto ${ }^{15}$. De la poesía española, son valiosos, por ejemplo, algunos romances tradicionales (el del prisionero, el del infante Arnaldos), las églogas primera y tercera de Garcilaso, sonetos y romances de Lope de Vega, la «Canción del pirata» de Espronceda, rimas de Bécquer, poesías de Rubén Darío, Juan Ramón Jiménez, Federico García Lorca. A continuación se pueden utilizar poemas que combinen esos valores de sonido e imaginería con una especial disciplina y artificio: por ejemplo, de Fray Luis de León, Góngora y Quevedo ${ }^{16}$. El orden de las lecturas y los trabajos con los textos se destinarán a consolidar la visión de la imaginería literaria, a aguzar la sensibilidad para los matices y cambios, y a desarrollar una capacidad de percepción y comprensión que reúna sonido, organización verbal e imágenes ${ }^{17}$.

\footnotetext{
${ }^{15}$ Las lecturas clásicas son fundamento de la educación, y no complemento para relegarse a una asignatura optativa de «Cultura Clásica». Por ejemplo, Curtius (197) considera que la Bucólica I de Virgilio fue el inicio de la educación en latín desde tiempos del Imperio Romano hasta el siglo XIX, y si uno la desconoce carece de una clave de acceso a la literatura occidental.

${ }^{16}$ Las listas de lecturas que propone Frye (2000: 204, 238-39) incluyen baladas, canciones isabelinas, sonetos de Shakespeare, poesía de Donne, Burns, Blake, Dickinson, Wordsworth y Tennyson para los primeros años, y después Swift, Pope, A. E. Housman. El primer volumen de la serie Literature: Uses of the Imagination contiene abundante poesía: Blake, Byron, Wordsworth, Shelley, Longfellow, Dickinson, Yeats, Dylan Thomas, y canciones de los Beatles y Paul Simon. En cuanto a la presencia de Góngora en la enseñanza media, véase en Carreira un alegato y alguna orientación.

${ }^{17}$ En la secuencia de las lecturas importa su relación con aspectos fundamentales del imaginario, no su cronología. No es necesario decidir cuál es la época literaria más adecuada o más importante para la enseñanza (preocupación que aflora en Alarcos, Alvar, Amorós, Bustos, Moreno Báez, Rico y Rozas en Lázaro 1974: 23, 31-32, 46, 84-85, 118$19,129,159-60)$. Entre los trabajos que comento, Literature: Uses of the Imagination es ahistórico: textos clásicos, bíblicos, folclóricos y modernos aparecen agrupados según fábulas y arquetipos; The Practical Imagination combina lo histórico y lo sistemático: se divide en tres grandes capítulos de narrativa, poesía y drama; el primero es enteramente sistemático, según estructuras, técnicas de narración, etc.; el segundo tiene un apartado sistemático y otro cronológico; el último ordena las piezas cronológicamente, con introducciones históricas. Otras aproximaciones coinciden en anteponer a la historia los temas, tópicos y técnicas: Macé (464-65) y Favry (485-87) exponen que la lectura y
} 
Para la narrativa, siguen siendo fundamentales los motivos y estructuras descubiertos en cuentos, mitos, leyendas y relatos bíblicos. Algunos planes sugieren que se recojan en las primeras lecturas literarias, que ya pueden ser verdaderos textos clásicos, completos o en fragmentos: la Iliada, la Odisea, la Eneida, las Metamorfosis, libros de la Biblia, el Cantar de mio Cid y romances épicos castellanos, el Cantar de Roldán y el de los Nibelungos; también se puede ampliar con la materia artúrica y nórdica ${ }^{18}$.

Después, se abordarán obras de contenido más cercano a la experiencia verosímil y corriente, desde la picaresca del Siglo de Oro hasta la novela histórica y realista de los siglos XIX y XX ${ }^{19}$. Con ellas se realizará un triple trabajo: descubrir las analogías estructurales con mitos y leyendas; estudiar con más detenimiento las fábulas de tipo trágico e irónico, que predominan en la literatura moderna; y analizar técnicas de narración como la identidad y conocimiento del narrador, el punto de vista, etc. ${ }^{20}$ También

estudio de poesías agrupadas según temas y motivos permite trazar mapas de universos imaginarios, comparar los textos de manera que resalten los aspectos formales, y contemplar la literatura como una conversación prolongada en que se van descubriendo nuevas perspectivas. Medina, Escobar y Oliver ofrecen una antología temática de poemas con orientaciones didácticas; Gómez Martín ha preferido un criterio más bien estructural, pero también es interesante desde el punto de vista de la imaginería. Morera ofrece una propuesta para el estudio del arquetipo «fuente» en la escuela.

18 Ver «An Articulated English Program»14; Frye 2000: 239; en Literature: Uses of the Imagination, se atienden primero los cuatro tipos de fábula (en dos volúmenes titulados Circle of Stories, 1 y 2), y después se dedican tres volúmenes a la Biblia y sus ecos (The Garden and the Wilderness, The Temple and the Ruin y The Peaceable Kingdom), y otros tres a la mitología clásica (Man the Mythmaker, The Perilous Journey y Man The Voyager). Esquer (97-122) y Castro (271-334) dedican capítulos a la épica clásica, a la épica medieval castellana y al romancero, y destacan su valor educativo y sobre todo la adecuación del romancero a las capacidades de lectura de los alumnos. En cuanto a las traducciones y versiones necesarias, está claro que debe asegurarse su calidad, y no conviene prescindir del verso: del Cantar de mio Cid existen las modernizaciones de Pedro Salinas y de F. Marcos Marín; para las Bucólicas y Geórgicas de Virgilio, poemas de Horacio, pasajes de la Biblia como los Salmos y el Libro de Job, hay que recordar que existen traducciones de uno de los mayores clásicos castellanos, Fray Luis de León; recientemente van apareciendo traducciones modernas en verso de la Iliada, la Odisea y la Eneida.

19 «An Articulated English Program» (14) sugiere el Lazarillo como lectura en el comienzo de la enseñanza media; es la primera obra en lengua moderna no inglesa que proponen (las demás para esa etapa son Robinson Crusoe, A Tale of Two Cities, The Great Meadow, Pride and Prejudice, David Copperfield, Jane Eyre, The Scarlett Letter, Arrowsmith, The Red Badge of Courage). Frye (2000: 239) propone comenzar por leyenda, mito y cuento de hadas, pasar a Tom Sawyer y a Dickens, entre otros, y por último (en lo que aquí se presenta como cuarta etapa) a Poe, Hawthorne y Melville.

${ }^{20}$ Para esta área la obra de Frye no proporciona orientaciones suficientes (apenas hay sino menciones del punto de vista y el conocimiento del narrador, por ejemplo en The Practical Imagination 2-5); habría que contar con los desarrollos de la narratología (por ejemplo, Booth, Genette). Verrier ofrece un ejemplo de análisis narratológico de novelas del XIX y el XX en enseñanza secundaria. 
puede comenzar ya la lectura de teatro antiguo y moderno; el análisis de estructura y fábula puede ser semejante al de la narrativa, pero ha de destacarse lo que aporta específicamente el medio de la escena.

Hacia el final de esta etapa es posible emprender el estudio de áreas especialmente técnicas y sistemáticas, como la versificación, la retórica, y el estudio de los grandes modos lírico, narrativo y dramático, con sus géneros históricos. Los alumnos pueden descubrir que tales disciplinas enriquecen y precisan su comprensión de las obras que han ido conociendo y valorando ${ }^{21}$.

La capacidad crítica de los alumnos ha de estimularse y orientarse en dos direcciones, una hacia dentro del texto literario, y otra hacia fuera. La primera se guía por preguntas del tipo: «Esto (esta palabra, este verso, esta imagen, episodio, personaje...), ¿qué hace aquí?, ¿qué justificación tiene?, ¿qué aporta?». Se trata de buscar respúestas en los repertorios de la imaginación literaria: una convención, la verosimilitud de la trama, un valor simbólico, etc. De esa manera se aprende a descubrir lo particular, a referir a lo general, a no pasar por alto nada que pueda tener sentido. En la segunda dirección, las preguntas esenciales son: «¿Es esto verdad?», y «¿para qué vale?». Así, se accede a un contexto histórico, cultural, político, social, económico, al cual las obras responden y ante el cual toman postura (con todo, no se debe olvidar que respuesta y postura son literarias, imaginativas, sujetas a convenciones; traducir inmediatamente el texto a programas políticos o sociales sería un error de método). Una segunda fase de estas preguntas traslada la obra al contexto actual: «ipara qué vale ahora?», «¿realmente vale para algo? ${ }^{22}$. Está claro que no se puede imponer la admiración, ni siquiera el respeto, mucho menos el sentido vinculante de lo clásico o canónico; pero sí cabe esperar de toda esta planificación que la relevancia contemporánea de las obras será mayor para quienes hayan desarrollado la capacidad de leerlas atentamente y situarlas en el orden total de palabras que la humanidad va componiendo.

En este punto hay que plantear el papel de la Historia de la Literatura. Esa disciplina ha sido el eje de la enseñanza literaria al menos desde

\footnotetext{
${ }^{21}$ García Galiano comenta: «Piénsese en el creciente éxito de las docencias literarias 'no académicas', me refiero al auge de talleres, escuelas de letras, seminarios de 'escritura creativa', etc. [...] que a fin de cuentas han regresado, asumiendo los modelos de análisis de la moderna Teoría Literaria, ¡a las antiguas y denostadas artes de la Retórica y la Poética!» (en Garrido 2000: 340).

${ }^{22}$ Esta última aproximación es bastante delicada: Amorós anima a relacionar la literatura con la «vida cotidiana» de los alumnos, pero Rico advierte que esa tarea puede entrañar ejercicios de alegoría y renunciar a la especificidad de lo literario (en Lázaro 1974: 46 y 123-25). Otro aspecto de la cuestión es lo que llama Colomer (1996: 135) «la familiarización con el circuito social del fenómeno literario», es decir, la producción, distribución y consumo de libros y obras teatrales en la actualidad.
} 
mediados del siglo $\mathrm{XIX}^{23}$. En las últimas décadas, tal situación ha recibido críticas porque fácilmente da lugar a un historicismo excesivo y a que los datos memorísticos sustituyan la lectura de obras ${ }^{24}$. Por justas que sean esas consideraciones, y pese al predominio de enfoques sistemáticos en las nuevas tendencias didácticas - sobre todo la atención a los géneros literarios-, una visión histórica no puede desecharse. Francisco Rico ha escrito que «en un país de gentes bien educadas nadie debiera dejar las enseñanzas comunes y pasar al tajo o a la universidad sin haber alcanzado el estado en que la lectura fuerza ya a poseer algunos rudimentos de historia literaria» (en Lázaro 1974: 129). Frye también sugiere que la enseñanza media debe incluir esa disciplina, pero quizá sea innecesario ocupar a los alumnos detenidamente con ella; propone distribuir cierta información histórica al hilo de los textos principales, y usar como material de lectura biografías de autores importantes, de tal manera que bastaría, al final, un breve periodo para repasar en síntesis esos conocimientos y abordar algunos problemas específicos de historiografía (Frye 2000: 205, 240).

\section{CUARTA ETAPA: HASTA LOS DIECIOCHO AÑOS}

Los últimos dos años de enseñanza media se pueden destinar al estudio crítico exigente de obras más complejas. La capacidad para entender y describir temas y estructuras se da ya por supuesta; ahora se enfocan cuestiones de textura verbal, ambigüedad e intertextualidad. Las lecturas propias para esta etapa son la poesía difícil, desde los grandes poemas gongorinos hasta los textos más complejos del Grupo del 27 y de los contemporáneos; la narrativa compleja y simbólica, desde el Quijote hasta Borges; y asimismo piezas teatrales difíciles, desde el Siglo de Oro hasta el presente. También es oportuno incluir obras no hispánicas; como ya se han visto los clásicos, puede hacerse un recorrido por las lenguas modernas, con Dante, Petrarca, Montaigne, Shakespeare, Molière, Racine, Goethe, Melville, Whitman, Tolstoi, etc. La organización de la materia puede reforzar o bien la visión histórica, si antes fue insuficiente, ordenando las

${ }^{23}$ Colomer (1996: 123-30) presenta una síntesis de los cambios en la educación literaria y las innovaciones más recientes; Baasner expone ampliamente el desarrollo de la historiografía literaria española y su implantación en la enseñanza; Galván muestra además el giro historicista de la poética en la segunda mitad del XIX, y la repercusión de estos fenómenos en el conocimiento y la lectura de una obra concreta (el Cantar de mio Cid).

${ }^{24}$ Ver, por ejemplo, las opiniones de Dámaso Alonso, Andrés Amorós y Enrique Moreno Báez en Lázaro 1974: 17, 41-42, 105; Coseriu 32; Mendoza 12-13. Ver también la crítica de Barthes y de Idt a la enseñanza de la historia literaria en Francia, y las breves consideraciones teóricas de Todorov (634) como conclusión de las jornadas que dirigió con Doubrovsky. 
lecturas cronológicamente (por ejemplo, de la Edad Media al siglo XVIII en el primer curso, y los siglos XIX y XX en el segundo), o bien el estudio sistemático, por géneros o por temas ${ }^{25}$.

\section{CIRCUNSTANCIAS Y PERSPECTIVAS}

Dentro del sistema escolar español actual, las posibilidades de llevar a cabo planes como los descritos varían según los tramos. Las leyes y las propuestas del Ministerio de Educación son relativamente flexibles. Las etapas primera y segunda expuestas aquí corresponden a la Enseñanza Infantil y la Primaria. En las orientaciones oficiales se habla de familiarizar a los niños con las tradiciones literarias orales y escritas, y despertarles «curiosidad e interés» por la literatura en el primer ciclo de Primaria; «iniciativa» lectora en el segundo; «criterios y gustos personales» y «autonomía» en el tercero ${ }^{26}$. Cualquier programa más concreto es viable en ese contexto. Lo importante es que tenga en cuenta el objetivo general de la educación literaria: no basta que a los niños les guste leer y lo hagan por su cuenta; es necesario que sus lecturas los dispongan en la mejor situación para avanzar en las etapas superiores, con el entrenamiento en el ritmo, la metáfora y la narración, y la familiaridad con mitos, leyendas y relatos bíblicos.

En la enseñanza media, los planes recientes incluyen las materias literarias como un apartado entre varios dentro de las asignaturas de «Lengua y Literatura Castellanas». La Secundaria Obligatoria comienza con una introducción a los géneros literarios y a los recursos del lenguaje literario; el segundo curso se dedica a los géneros narrativo, lírico y dramático. El segundo ciclo comprende la historia de la literatura: de la Edad Media al siglo XVIII un curso, y los siglos XIX y XX en el siguiente ${ }^{27}$. Por último, el plan de Bachillerato presenta, otra vez, dos cursos de historia de la literatura ${ }^{28}$.

Es evidente que la enseñanza media necesita cambios; para empezar, una ampliación del espacio para la literatura. Además, los primeros cursos

\footnotetext{
${ }^{25}$ En Literature: Uses of the Imagination, se prefiere el enfoque sistemático, con cuatro volúmenes que retoman los cuatro tipos de fábula y profundizan en ellos (A World Elsewhere: Romance; A World Enclosed: Tragedy; The Ways of the World: Satire and Irony; A World Remade: Comedy). La antología The Practical Imagination (para cursos de literatura en la universidad) combina lo sistemático y lo cronológico, como se ha expuesto en la nota 17.

${ }^{26}$ Ver Lengua castellana y literatura: Primaria 62-63.

27 Ver Educación Secundaria Obligatoria 83, 85, 87, 90; también Lengua castellana y literatura: Secundaria Obligatoria 72-73.

${ }^{28}$ Ver Bachillerato 46-51, en plan nuevamente sancionado como anexo al Real Decreto 938/2001, en BOE 7-IX-2001.
} 
resultan abstractos (tanto más, si no han tratado la literatura con cierto sistema en los años anteriores), y después se da una redundancia, con la historia de la literatura en el segundo ciclo de ESO y en Bachillerato. Según los planes que se han examinado aquí, los dos primeros años podrían dedicarse a pasajes importantes de los clásicos, la Biblia y la historia y ficción medievales, y a la poesía, con especial atención al sistema de imágenes. Después se atendería a la narración y al teatro, y al final de la Secundaria Obligatoria se estudiaría retórica, métrica, géneros e historia de la literatura. Este tramo es el menos compatible con los planes oficiales. En el Bachillerato, la lectura crítica detenida de grandes obras, especialmente si se hace en orden cronológico, puede acomodarse al plan actual, que además es flexible ${ }^{29}$.

En conclusión, estas páginas pretenden mostrar un modelo que ayude a elaborar planes de enseñanza de la literatura en el sistema educativo. Es evidente que deberían complementarlos otros muchos trabajos: formación del profesorado, preparación de libros de lectura y repertorios de textos que tengan en cuenta tanto las capacidades e intereses de los alumnos como el proceso total de aprendizaje, estudios sobre literatura infantil y juvenil. Es necesaria la colaboración continuada de profesores universitarios, de enseñanza media y de educación infantil; la investigación y la puesta en común de experiencias; el trabajo de expertos en literatura, y en pedagogía y psicopedagogía. Tan amplia tarea es uno de los mayores servicios que las instituciones de investigación y enseñanza superior pueden prestar a la sociedad, para que todos puedan tomar posesión de la humana herencia verbal e imaginativa, y con ella adquieran sus propias perspectivas y proyectos; en definitiva, para que sean verdaderamente más libres.

\section{OBRAS CITADAS}

«An Articulated English Program: A Hypothesis to Test». Publications of the Modern Language Association of America 74, n. 4.2 (sept. 1959): 13-19.

BAASNER, Franz, Literaturgeschichtsschreibung in Spanien von den Anfängen bis 1868. Frankfurt a. M.: Klostermann, 1995

Bachillerato: enseñanzas mínimas. Madrid: Ministerio de Educación, Cultura y Deporte, Subdirección General de Información y Publicaciones, 2001

BARTHES, Roland, «Réflexions sur un manuel». Doubrovsky y Todorov, 170-77.

Benito, Rosa M. ${ }^{a}$, M. $^{a}$ Antonia Montes, M. ${ }^{a}$ Jesús PÉReZ Zorrilla y Jesús Ángel REMACHA, «Panorama de la literatura infantil en la escuela». Galán, Gúgel, Sainz de Vicuña y Suárez, 59-78.

${ }^{29}$ Cao (42) sugiere una variedad de distribuciones del contenido literario de las asignaturas en Bachillerato: la mera división cronológica que presenta el $B O E$; un enfoque sistemático en el primer curso y uno histórico en el segundo; o una división principalmente genérica, con lírica y teatro en primero, y narración y ensayo en segundo. 
Booth, Wayne C., The Rhetoric of Fiction. Chicago: The University of Chicago Press, 1961.

Bravo-Villasante, Carmen, Historia de la literatura infantil española. 3. ${ }^{a}$ ed. Madrid: Doncel, 1969.

Campbell, Mary A., R. P. McDonald, J. E. Parsons, A. Douglas Sparks y Donald F. THEALl, «Report of the English Study Committee», Frye 1962, 19-78.

CAO MARTínez, Ramón, Lengua Castellana y Literatura I: materiales didácticos. Madrid: Ministerio de Educación y Ciencia, Centro de Publicaciones, 1995.

CARREIRA, Antonio, «La décima de Góngora al Conde de Saldaña: comentario de texto, y reflexiones sobre la enseñanza de la Literatura en el Bachillerato», Rilce: Revista de Filología Hispánica 9 (1993): 170-93.

CASONA, Alejandro, Flor de leyendas: lecturas literarias para niños. 2. ${ }^{a}$ ed. Madrid: Espasa-Calpe, 1934.

Castro Alonso, Carlos A., Didáctica de la literatura. Salamanca: Anaya, 1971.

COLOMER, Teresa, «La didáctica de la literatura: temas y líneas de investigación e innovación», La educación lingüística y literaria en la enseñanza secundaria. Coord. Carlos Lomas. Cuadernos de formación del profesorado, Educación Secundaria, 1. Barcelona: ICE Universitat de Barcelona - Horsori, 1996, 123-42.

COLOMER, Teresa, Introducción a la literatura infantil y juvenil. Madrid: Síntesis, 1999.

COSERIU, Eugenio, «Acerca del sentido de la enseñanza de la lengua literaria». Galán, Gúgel, Sainz de Vicuña y Suárez, 13-32.

CRUZ RUEDA, Ángel, Las gestas heroicas castellanas contadas a los niños: el rey Rodrigo, Bernardo del Carpio, los siete infantes de Lara, el Conde Fernán González, el Cid. Madrid: Biblioteca Nueva, 1931.

CURTIUS, Ernst Robert, Europäische Literatur und Lateinisches Mittelalter. $9^{\text {a }}$ ed. Bern - München: Francke, 1978.

Doubrovsky, Serge y Tzvetan Todorov, dirs., L'Enseignement de la Littérature (Centre Culturel de Cerisy-la-Salle, 22 au 29 juillet 1969). Paris: Plon, 1971.

Educación Secundaria Obligatoria: enseñanzas mínimas. Madrid: Ministerio de Educación, Cultura y Deporte, Subdirección General de Información y Publicaciones, 2001.

ESQUER TORRES, Ramón, Didáctica de la literatura. Madrid: Alcalá, 1969.

FAVRY, Roger, «L'enseignement de la littérature et l'expression libre». Doubrovsky y Todorov, 471-89.

FRYE, Northrop, Anatomy of Criticism: Four Essays. Princeton: Princeton University Press, 1957.

- Fables of Identity: Studies in Poetic Mythology. New York - London: Harcourt, Brace and World Inc., 1963.

- The Secular Scripture: A Study of the Structure of Romance. Cambridge, MA: Harvard University Press, 1976.

- Myth and Metaphor: Selected Essays, 1974-1988. Ed. Robert D. Denham. Charlottesville - London: University Press of Virginia, 1990.

- Northrop Frye's Writings on Education. Ed. Jean O'Grady y Goldwin French. Toronto: University of Toronto Press, 2000.

FRYE, Northrop, ed., Design for Learning: Reports Submitted to the Joint Committee of the Toronto Board of Education and the University of Toronto. [Toronto]: University of Toronto Press, 1962.

GalÁN LóPEZ, Isabel, Concepción GúGEl GiméneZ, Paloma SAINZ DE VicuÑa y Juan Luis SUÁREZ GRANDA, eds., Innovación en la enseñanza de la lengua y la literatura (Actas del Simposio "Innovación en la enseñanza de la lengua y la literatura española», Madrid, Universidad Complutense, 4-8 de junio de 1984). Madrid: Ministerio de Educación y Ciencia, Subdirección General de Formación del Profesorado, 1987. 
Galván, Luis, El «Poema del Cid» en España, 1779-1936: recepción, mediación, historia de la filología. Pamplona: Eunsa, 2001.

GARCía RIVERA, Gloria, Didáctica de la Literatura para la Enseñanza Primaria y Secundaria. Madrid: Akal, 1995.

GARRIDO Gallardo, Miguel Ángel, La Musa de la Retórica: problemas y métodos de la Ciencia de la Literatura. Madrid: CSIC, 1994.

GARRIDO, Miguel Ángel, Nueva introducción a la teoría de la literatura. Madrid: Síntesis, 2000.

GENETTE, Gérard, Figuras III. Barcelona: Lumen, 1989.

Gómez MARTín, Fernando, Didáctica de la poesía en la Educación Secundaria. Madrid: Ministerio de Educación, Cultura y Deporte, 2002.

GonZÁlEZ, Luis Daniel, Bienvenidos a la fiesta: diccionario-guía de autores y obras: Literatura infantil y juvenil. Madrid: Cie Inversiones Editoriales Dossat 2000, 2001

IDT, Geneviève, «Pour une 'histoire littéraire' tout de même». Poétique 8 (1977): $167-74$.

LÁZARO CARRETER, Fernando, «Cuestión previa: el lugar de la literatura en la educación». El comentario de textos.' Madrid: Castalia, 1973, 7-29.

- Literatura y educación. Madrid: Castalia, 1974.

Literature: Uses of the Imagination. Ed. Alvin A. Lee, Hope Arnott Lee y W. T. Jewkes. 13 vols. New York: Harcourt Brace Jovanovich, 1972-1973.

Lengua castellana y literatura: Primaria. Madrid: Ministerio de Educación y Ciencia, 1992.

Lengua castellana y literatura: Secundaria Obligatoria. Madrid: Ministerio de Educación y Ciencia, 1992.

LÓPEZ TAMÉS, Román, Introducción a la literatura infantil. 2. ${ }^{a}$ ed. Murcia: Universidad, Secretariado de Publicaciones, 1990.

MACÉ, Gérard, «Enseigner la poésie pour reapprende à lire». Doubrovsky y Todorov, 463-70.

MACPHERSON, Jay, Four Ages of Man: The Classical Myths. Toronto: MacMillan, 1962.

MEDINA RIVILla, Antonio, Julián EsCOBAR RUESCAS y Francisco OlIVER FORNER, Didáctica de la poesía: antología poético-temática de autores españoles. Madrid: Edilibro, 1984.

Mendoza FIllola, Antonio, Literatura comparada e intertextualidad: una propuesta para la innovación curricular de la literatura (Educación secundaria). Madrid: La Muralla, 1994.

Moreno Alonso, Víctor, El juego poético en la escuela. Pamplona: Pamiela, 1989.

MORERA ESCARRÉ, Montserrat, «Instrumentos del trabajo intelectual: palabras con aura, diccionarios y literatura». Noya y Posada, 423-36.

MUÑOZ LÓPEZ, Miguel, «La creación literaria en la escuela». Galán, Gúgel, Sainz de Vicuña y Suárez, 293-300.

Noya Beiroa, Raquel y Ana Luisa Posada Luaces, eds., Actas del VII Simposio Nacional de la Federación de Asociaciones de Profesores de Español (11 al 14 de septiembre de 1997, Santiago de Compostela). Lugo: Servicio de Publicaciones, Diputación Provincial de Lugo, 1999.

ORIVE CASTRO, Esteban, ed., Literatura: creación y enseñanza (Actas del VI Simposio Nacional de la Federación de Asociaciones de Profesores de Español). Madrid: Ediciones del Orto, 1997.

Pelegrín, Ana, «Taller de poesía». Galán, Gúgel, Sainz de Vicuña y Suárez, 301-13.

The Practical Imagination: Stories, Poems, Plays. Ed. Northrop Frye, Sheridan Baker y George Perkins. New York: Harper \& Row, 1980.

REYZÁBAL, María Victoria, «Didáctica de la literatura». Didáctica de la lengua y la literatura. Coord. Joaquín Serrano y José Enrique Martínez. Barcelona: Oikos-Tau, 1997, 241-66. 
RODARI, Gianni, Gramática de la fantasía: introducción al arte de inventar historias. Trad. Mario Merlino. 4. ${ }^{a}$ ed. Barcelona: Ediciones del Bronce, 1998.

SLOAN, Glenna Davis, The Child As Critic: Teaching Literature in Elementary and Middle Schools. 3. ${ }^{\mathrm{a}}$ ed. New York - London: Teachers College Press, 1991.

TODOROV, Tzvetan, «Conclusion». Doubrovsky y Todorov, 627-35.

VERRIER, Jean, «Lectures de romans». Doubrovsky y Todorov, 453-62. 


\title{
RESUMEN
}

\section{Elementos para un plan de educación literaria, por Luis Galván.}

La educación literaria en primera y segunda enseñanza necesita una planificación comprensiva desarrollada a partir de los principios de la literatura y la ciencia literaria. Se presentan en esquema algunos planes que se han llevado a cabo de acuerdo con las ideas de Northrop Frye sobre literatura y educación, para que sirvan de guía a desarrollos similares en la enseñanza de la literatura española. Los planes deben comenzar con cuentos populares y fantásticos y poesía popular, y después incluir mitos, leyendas nacionales y la Biblia, para desarrollar en los alumnos sensibilidad para el sonido, los símbolos y las estructuras; sobre esta base, en segunda enseñanza se estudiarían de forma continua las grandes obras de poesía, narrativa y drama.

Palabras clave: Enseñanza de la literatura, metáfora y fábula, Northrop Frye.

\begin{abstract}
Literary education in Primary and Secondary School must follow comprehensive plans based on the actual principles of Literature and Criticism. In English-speaking countries during the last decades plans have been based on the literary and educational thought of Northrop Frye. This article overviews these theories and in-class manuals to provide guidelines for similar developments to teach Spanish Literature. These pedagogical plans should start with folk and fairy tales and popular rhymes, later include myths, national legends and the Bible, in order to develop the students' sense of sound, symbol and pattern, as a basis for the continuous study of high poetry, fiction and drama in the Secondary School.
\end{abstract}

Key words: Literary education, metaphor and myth, Northrop Frye. 